\title{
Frequent attendance in primary care: comparison and implications of different definitions
}

\author{
Juan V Luciano, Ana Fernández, Alejandra Pinto-Meza, Leila Luján, Juan A Bellón, \\ Javier García-Campayo, María T Peñarrubia, Rita Fernández, Marta Sanavia, \\ María E Blanco, Josep M Haro, Diego J Palao and Antoni Serrano-Blanco
}

\begin{abstract}
\section{Background}

The diversity of definitions of frequent attendance in the literature hampers comparison of their precision, validity, and associated factors.

Aim

To examine different definitions of frequent attendance in order to identify the sociodemographic and clinical factors associated with frequent attendance in primary care, according to each definition.

\section{Design of study}

One-phase cross-sectional study.

Setting

Seventy-seven primary care centres in Catalonia, Spain.

Method

A total of 3815 primary care patients were interviewed between October 2005 and March 2006. Three definitions of frequent attendance were tested: (1) frequent attenders as the top $25 \%$ and the top $10 \%$ consulting patients; (2) frequent attenders as the top $25 \%$ and the top $10 \%$ consulting patients stratified by age and sex; and (3) frequent attenders as the top 25\% and the top $10 \%$ consulting patients stratified by the presence of physical/mental conditions (patients with only mental disorders, with only chronic physical conditions, with comorbid conditions, and with no condition). Multilevel logistic regressions were used.
\end{abstract} Results

The following factors were systematically related to frequent attender status: being on sick leave, being born outside of Spain, reporting mental health problems as the main reason for consulting, and having arthritis/rheumatism, or bronchitis. Major depression was related to frequent attendance in two of the three definitions. The factor 'GP' was related to frequent attendance when the top decile cut-off point was used. The models with a $10 \%$ cut-off point were more discriminative than those with a $25 \%$ cut-off point: the area under the receiver operating characteristic curve for models with a $25 \%$ cut-off and a $10 \%$ cut-off ranged between 0.71 (95\% confidence interval $[\mathrm{Cl}]=0.70$ to $0.73)$ and $0.75(95 \% \mathrm{Cl}=0.74$ to 0.77$)$ and between 0.79 (95\% $\mathrm{Cl}=0.78$ to 0.81$)$ and $0.85(95 \% \mathrm{Cl}=0.83$ to 0.86$)$, respectively.

\section{Conclusion}

The way frequent attendance is defined is of crucial importance. It is recommended that a more discriminative definition of frequent attendance is used (the top 10\%).

\section{Keywords}

chronic illness; frequent attendance; health services; mental disorders; primary health care; utilisation.

\section{INTRODUCTION}

It is well known that a high rate of visits to primary care are made by a small proportion of patients, who generate a great cost for public health systems and considerable workload and frustration to GPs. ${ }^{1,2}$

Previous studies have shown that frequent attenders have more chronic physical conditions, ${ }^{3}$ mental disorders ${ }^{4-6}$ and psychological distress, ${ }^{7}$ poorer health beliefs, ${ }^{8}$ and more need of information and/or reassurance, ${ }^{9}$ compared with non-frequent attenders. However, the use of diverse definitions of

JV Luciano, PhD, psychologist, RedIAPP postdoctoral researcher; A Fernández, MSc, psychologist, RedIAPP predoctoral researcher; A Pinto-Meza, PhD, psychologist; A Serrano-Blanco, $M D, P h D$, psychiatrist, coordinator of the Urgencies and Partial Hospitalization Unit; L Luján, MSc, statistician, Sant Joan de Déu, Servicios de Salud Mental y Fundación Sant Joan de Déu; Red de Investigación en Actividades Preventivas y Promoción de la Salud (RedIAPP), Barcelona, Spain. JA Bellón, MD, PhD, GP, RedIAPP, Barcelona; Centro de Salud 'El Palo', Unidad de Investigación del Distrito de Atención Primaria de Málaga \& Departamento de Medicina Preventiva, Universidad de Málaga, Spain. J García-Campayo, $M D, P h D$, psychiatrist, director of the Somatoform Disorders Unit, RedIAPP, Barcelona; Hospital Universitario Miguel Server, Zaragoza, Spain. MT Peñarrubia, $M D, G P ;$ R Fernández, MD, GP, RedIAPP; Centro de Salud 'Bartomeu Fabrés Anglada', Barcelona, Spain. M Sanavia, MD, GP; ME Blanco, MD, GP, Centro de Salud 'Bartomeu Fabrés Anglada', Barcelona, Spain. JM Haro, MD, PhD, psychiatrist, director of the Sant Joan de Déu, Servicios de Salud Mental y Fundación Sant Joan de Déu, Barcelona; Centro de Investigación Biomédica en Red en Salud Mental (CIBERSAM) Madrid, Spain. DJ Palao, MD, PhD, psychiatrist, Executive director of the Parc Tauli Mental Health, Corporació Sanitària Parc Tauli, Barcelona, Spain.

Address for correspondence Juan V Luciano, Unitat de Recerca i Desenvolupament. Sant Joan de Déu - Serveis de Salut Mental, C/ Doctor Antoni Pujadas 42 08830, Sant Boi de Llobregat, Barcelona, Spain. E-mail: jvluciano@sjd-ssm.com

Submitted: 1 March 2009; Editor's response: 11 May 2009; final acceptance: 17 June 2009.

(c)British Journal of General Practice

This is the full-length article of an abridged version published in print. Cite this article as: Br J Gen Pract 2010; DOI: 10.3399/bjgp10X483139. 
frequent attendance avoids a comprehensive interpretation of these findings. ${ }^{10,11}$

Pioneer studies usually established a cut-off in the distribution of visit frequency (the top quartile or decile of consultation rates) such that all patients consulting more frequently than this were defined as frequent attenders. A relatively recent definition, that is becoming increasingly popular, considers frequent attenders as a proportional part (highest $25 \%$ or $10 \%$ ) of all primary care patients, stratified by age and sex. However, neither definition takes into account that certain patients need to make more consultations than others. ${ }^{12}$ For instance, patients with comorbidity are usually more impaired, have a worse prognosis, and are more difficult to manage than those with a single mental/physical condition, which may explain the higher number of visits to general practice. ${ }^{13}$

In the present study, a two-stage approach to identify frequent attenders is proposed: (1) classifying patients into four categories according to their clinical profile (no pathology, only mental disorder, only chronic physical condition, physical and mental comorbidity), and (2) considering as frequent attenders those situated in the top quartile or decile of primary care consultations in each category. The main objectives were to propose and discuss different definitions of frequent attendance and to identify sociodemographic and clinical factors associated with frequent consultation to primary care according to each definition.

\section{METHOD}

The data collected in the Diagnostic and Assessment Study of Mental Disorders in Primary Care (DASMAP) study were used to perform the current work. ${ }^{14}$ The DASMAP was a cross-sectional epidemiological survey carried out in Catalonia (Spain) to assess the lifetime and 12-month prevalence of mental disorders in a representative sample of adult (>18 years) primary care attenders. Data were collected between October 2005 and March 2006 using a written interview. After a visit with a GP patients were offered the choice to participate in the DASMAP study and were evaluated in the primary care centres after giving written informed consent.

\section{Participants}

A stratified multistage probability sample without replacement was drawn in the DASMAP study. Replacement was prohibited to ensure that every individual had a known probability of selection. The sampling frame was the seven health regions of Catalonia.

Stage 1 was selection of the primary care centres within each health region (there were 350 primary

\section{How this fits in}

To date, the use of different definitions of frequent attendance has prevented development of a comprehensive knowledge of this phenomenon. This is thought to be the first study demonstrating that beyond the definition, certain sociodemographic characteristics and medical conditions are significantly related to high consultation to general practice. Moreover, the cut-off point employed to select frequent attenders was found to be of crucial importance. It is recommended that a more discriminative definition of frequent attendance is used (the top 10\%).

care centres in Catalonia in 2005). The number of primary care centres to be selected in each region was proportional to the population of the region. However, in order to have a minimum set of interviews even in the smaller regions, at least six primary care centres were chosen per region. The probability of selection of each primary care centre was related to the population of the catchment area covered by the centre. Eighty primary care centres were selected to participate and two refused (97.5\% acceptance rate).

In stage 2 , all GPs $(n=913)$ of the primary care centres were invited to participate. A total of $618 \mathrm{GPs}$ (67.7\%) participated in the study.

In stage 3, patients were selected from the daily list of all patients with an appointment with each of the participating GPs, using a systematic sampling strategy. A total of 5402 patients were randomly selected. Among these, 654 (12.1\%) did not attend the visit with the GP, so they were not invited to participate in the DASMAP study. A total of 4748 were invited to participate. Among these, 764 (16.1\%) did not accept the offer to participate and 164 (3.5\%) were excluded because they showed cognitive impairment severe enough to preclude an adequate interview, leaving a study sample of 3820 participants from 78 primary care centres. One of the primary care centres was excluded from the statistical analyses because of data loss. Therefore, the analysed sample comprised 3815 patients $(80.3 \%$ of the patients initially invited) with a mean age of 54.3 years (standard deviation [SD] = 17.31; range 18-97 years). Females represented $63 \%$ of the sample.

\section{Definitions of frequent attendance}

Three different definitions of frequent attendance were considered, each divided into two according to a 1-year number of visits cut-off: (1) frequent attenders as the top $25 \%$ and the top $10 \%$ consulting patients during a 1-year period; (2) frequent attenders as the top $25 \%$ and the top $10 \%$ consulting patients during a 1-year period stratified by age and sex; and (3) frequent attenders as the top $25 \%$ and the top 


\begin{tabular}{|c|c|c|c|c|}
\hline & $\begin{array}{c}\text { Cut-off at } \\
\text { 75th percentile }\end{array}$ & $\begin{array}{l}\text { Mean number } \\
\text { of visits (SD) }\end{array}$ & $\begin{array}{c}\text { Cut-off at 90th } \\
\text { percentilea }\end{array}$ & $\begin{array}{l}\text { Mean number } \\
\text { of visits (SD) }\end{array}$ \\
\hline $\begin{array}{l}\text { Definition 1: } \\
\text { without stratifying }\end{array}$ & $>8(853)$ & $15.59(9.47)$ & $>12(328)$ & $23.05(11.89)$ \\
\hline \multicolumn{5}{|c|}{ Definition 2: stratified by sex and age, years } \\
\hline \multicolumn{5}{|l|}{ Women } \\
\hline $18-24$ & $>6(28)$ & $10.54(3.11)$ & $>10(10)$ & $13.10(3.84)$ \\
\hline $25-34$ & $>7$ (67) & $15.24(8.98)$ & >12 (30) & 21.57 (10.30) \\
\hline $35-49$ & $>7(130)$ & $15.55(10.99)$ & $>12(53)$ & $23.43(13.15)$ \\
\hline $50-64$ & $>8$ (182) & $15.57(9.94)$ & $>12(64)$ & 23.91 (13.15) \\
\hline$\geq 65$ & $>9$ (167) & $14.88(8.80)$ & $>12$ (56) & 22.36 (12.09) \\
\hline \multicolumn{5}{|l|}{ Men } \\
\hline $18-24$ & $>5(14)$ & $8.5(4.73)$ & $>7(5)$ & $12.40(6.54)$ \\
\hline $25-34$ & $>5(30)$ & $12.73(8.91)$ & $>10(11)$ & $21.36(9.74)$ \\
\hline $35-49$ & $>6(62)$ & $16.40(11.58)$ & $>12(24)$ & $26.92(12.73)$ \\
\hline $50-64$ & $>8(91)$ & $14.88(6.41)$ & $>12(35)$ & $20.69(7.21)$ \\
\hline$\geq 65$ & $>10(99)$ & $17.92(10.35)$ & $>13(50)$ & $23.76(11.99)$ \\
\hline \multicolumn{5}{|c|}{ Definition 3: stratified by physical/mental conditions } \\
\hline Without pathology & $>5$ (89) & $10.13(6.87)$ & $>8$ (44) & $13.77(8.33)$ \\
\hline Only physical & $>7$ (555) & $13.86(8.08)$ & $>12(163)$ & $22.11(10.97)$ \\
\hline Only mental & $>6(27)$ & $13.07(5.65)$ & $>10$ (13) & $17.69(4.75)$ \\
\hline Comorbid & $>10(225)$ & $19.94(11.99)$ & $>18(97)$ & 28.76 (13.88) \\
\hline
\end{tabular}

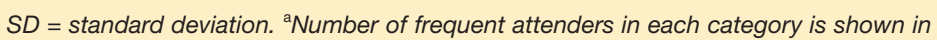
brackets after the cut-off point. heart attack, stroke, migraines, allergies, arthritis, back pain, neck pain, and diabetes. Responders were asked whether they had ever in their life experienced each of the symptom-based conditions in the checklist. In the case of conditions typically identified by medical diagnosis, responders were asked whether a doctor or other health professional had ever told them they had the condition.

- An adapted version of the Client SocioDemographic and Service Receipt Inventory (CSRI). ${ }^{18}$ The CSRI version used in this study was designed to collect data on health services utilisation during the previous 12 months. For the purposes of the present work, only face-to-face contacts between patients and GPs from the public sector were taken into account.

\section{Statistical analysis}

Multilevel logistic regression was used, with GP and primary care centre as random factors. Firstly, it was tested whether multilevel logistic regression was more appropriate than usual logistic regressions. When the null models including primary care centre as random factor were compared, likelihood ratio tests were very significant for all models. Secondly, a comparison was carried out between null models that included primary care centre and GP as random factors versus those with only primary care centre; likelihood ratio tests were also significant for the three definitions with the cut-off at the 90th percentile; however, they were not significant for the three definitions with the cut-off at the 75th percentile. That is, for the definitions of frequent attenders at the 90th centile, primary care centre and GP were used as random factors, and for the definitions at the 75th centile, only primary care centre was used as random factor. Intracluster coefficients (ICCs) of random components were calculated as follows: ${ }^{19} \sigma^{2} /\left(\sigma^{2}+\pi^{2} / 3\right)$. The ICCs of the primary care centres in the null models were: model 1 (cut-off $75 \%=0.0436$; cut-off $90 \%=0.0518$ ), model 2 (cut-off $75 \%=0.0380$; cut-off $90 \%=0.0573$ ), model 3 (cut-off $75 \%=0.0464$; cut-off $90 \%=0.0436$ ). The ICCs of the GPs were: model 1 (cut-off 90\% $=0.1011$ ), model 2 (cut-off 90\% = 0.0758), model 3 (cut-off $90 \%$ $=0.0886)$. Then, univariable multilevel logistic regression was performed. The final multivariable models included those variables that had been significant $(P \leq 0.20)$ in univariable analyses. ${ }^{20}$ 'Region' was retained because of an a priori assumption of clustering within region, although it had few categories $(n=7)$ that could be considered as random factors. ${ }^{21}$ The area under the receiver operating characteristic (ROC) curve was calculated to estimate the discriminative power of each model. The analyses were conducted using STATA (version 10). 


\section{RESULTS}

Table 2 shows that each definition had different variables in its multivariable model (only those clinical variables that reached significance in at least one of the definitions are displayed Table 2).

Variables that, independently of the definition, were systematically associated with frequent attender status were: being on sick leave; being born outside Spain; having mental health problems as the main reason for consulting; and having arthritis/rheumatism, or bronchitis.

When taking into account only definitions that consider the top quartile as frequent attenders, it was found that diabetes, migraines, and heart diseases were systematically related to frequent attendance. On the other hand, when using the top decile, having higher education was related to a decrease in the odds of being considered a frequent attender, independently of the definition. Being a woman was also associated with decreased odds of being considered a frequent attender in definitions using this cut-off point.

Definitions 1 and 2 were similar. Almost the same variables were found to be associated with frequent attendance. The main difference was found in definition 3. In contrast with the other models, where major depression was systematically associated with an increase in the odds of being a frequent attender, no mental disorder was positively associated with frequent attendance. Generalised anxiety disorder and any substance abuse disorders were related to a decrease in the odds of being considered a frequent attender in model 3 with the cut-off at the top quartile.

The area under the ROC curves ranged between 0.71 and 0.75 in the models with top quartile cut-off and between 0.79 and 0.85 in the models with the top decile cut-off.

\section{DISCUSSION}

\section{Summary of main findings}

The way frequent attendance is defined affects which variables are associated with this phenomenon. Definitions without stratification or stratified by sex and age provided similar results, whereas a definition taking into account health conditions as well as the cut-off used $(75 \%$ or $90 \%)$ had an impact on the random components of the model. It is of relevance that those models using the $90 \%$ cut-off point provided better discrimination between frequent and non-frequent attenders than those using the $75 \%$ cut-off point.

Beyond the definition, being on sick leave (highest odds ratio), being born outside of Spain, and reporting mental health problems as the main reason for consulting were associated in all models with increased odds of being considered a frequent attender. The only chronic physical conditions that were systematically associated with high consultation were arthritis/rheumatism and bronchitis.

\section{Strengths and limitations of the study}

The study design allowed selection of a sample that was representative of Catalan primary care patients and led to results that could be generalised to this wide population. On the other hand, the data were analysed considering three definitions of frequent attendance (two of them very close to previously reported definitions, and a new one considering wide categories of health conditions). This allows discussion of the concept of frequent attendance, its components, and its implications. In an effort to clarify the impact of mental disorders, well-known psychiatric instruments were administered.

The results of the study should be interpreted with caution because of the following limitations: first, there was no differentiation between whether patients or doctors initiated the contact, that is, it is not known which visits were spontaneously booked by patients and which by GPs (for instance, consultations for checking the evolution of patients with sickness leave). Second, data about health services utilisation were collected by means of a selfreport measure; such measures have been criticised for their inaccuracy. ${ }^{22}$ Third, the study focused on the sociodemographic and clinical characteristics of patients, not taking into account certain GPs' characteristics that might be associated with frequent attendance (age, sex, experience, type of training, style of practice, values, orientations, and attitudes). ${ }^{23,24}$

\section{Comparison with existing literature}

The variables that were found to be systematically associated with frequent attendance were in general consistent with those reported in other studies..$^{25,26}$ The individuals on sick leave (compared to those working) usually have the highest mean number of visits to the GP as well as to other healthcare providers. ${ }^{25}$ In line with the present results, Scaife et al found that South Asian and African-Caribbean immigrants were more likely to be frequent attenders than British patients. ${ }^{26} \mathrm{~A}$ lot of people from underdeveloped countries, characterised by high rates of unemployment, have migrated to Catalonia in the last decade to find employment, mainly in the industry and service sector. A considerable proportion of these immigrants belong to low social classes and suffer social isolation, factors that undermine their physical and mental health, and might explain their pronounced need to consult the primary care services.

Concerning chronic physical conditions, the present results are in line with those obtained in other Spanish 
Table 2. Multivariable multilevel regression analyses, showing odds ratio with $95 \%$ confidence intervals associated with each sociodemographic and clinical variable, by definition.

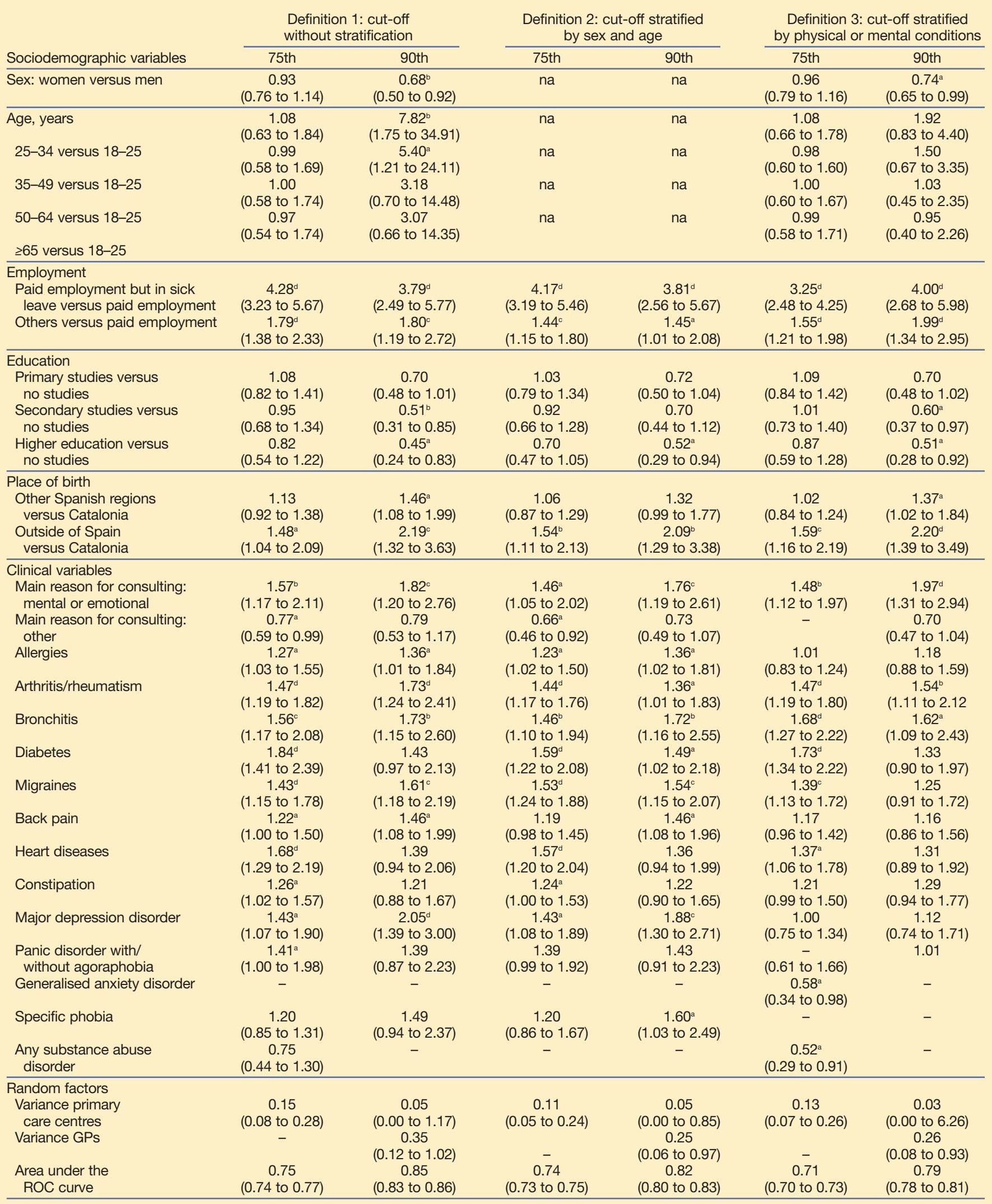

$n a=$ not applicable. $R O C=$ receiver operating characteristic. Significance levels: ${ }^{a} \mathrm{P}<0.05 ;{ }^{b} \mathrm{P}<0.01,{ }^{\mathrm{c}} \mathrm{P}<0.005,{ }^{\mathrm{d}} \mathrm{P}<0.001$. All models are also adjusted by health region. 
regions and other countries. . $^{1027,28}$ One study conducted in the city of Granada, Spain, found that chronic bronchitis was a very common disease among frequent attenders. ${ }^{27} \mathrm{Al}-\mathrm{Windi}$, by means of questionnaire surveys and computerised medical records, demonstrated that musculoskeletal, cardiopulmonary, and head symptom groups were significantly related to high past and prospective primary care consultation rates. ${ }^{28}$

The main difference between the present study and previous ones is related to definitions of frequent attendance. Definitions 1 and 2 (that do not consider patients' health conditions) are very close to previously published definitions, and are, in general, concordant to previous findings. However, when considering health conditions, results were different, especially regarding mental disorders. The review of Vedsted and Christensen concluded that mental health problems are associated with frequent attendance. ${ }^{1}$ This finding was not supported by the present definition considering health conditions. According to available clinical guidelines, ${ }^{29}$ mental disorders need frequent follow-ups. Not taking this into account could promote an over-estimation of the impact of these conditions on frequent attendance.

Mental illness is still stigmatised by both society and health professionals, who show adverse attitudes toward it. ${ }^{30}$ When defining frequent attendance adjusted by health conditions (definition 3), no mental disorder was associated with frequent attender status. However, it is possible that this could be related to some classification bias or to the way in which mental disorders were assessed in the present study. The SCID-I was used, which is more restrictive than criteria used in other studies (for example, assessment of depressive symptoms with general questionnaires). The fact that mental health problems as the main reason for consulting were systematically related to increased odds of being a frequent attender is in line with this. It is possible that depressive symptoms or emotional distress could explain frequent attendance, but it is important to notice that some depressive symptoms, like sadness or anhedonia, or a certain degree of emotional distress are not mental disorders.

\section{Implications for future research}

Two main implications could be derived from the present study. First, future studies should take into account the intracluster correlation of GP and primary care centre. Second, the way in which frequent attendance is defined has an impact on the factors associated with it and their discriminative power. The use of the top decile cut-off seems to be more recommended than the top quartile. Finally, it is important not only to take into consideration the patients' type of pathology, but also to make a subsequent explicit reflection about the possible reasons for the high rate of consultations of each frequent attender. ${ }^{31}$

\section{Funding body}

This study was funded by the 'Direcció General de Planificació i Avaluació Sanitària - Departament de Salut - Generalitat de Catalunya', Barcelona, Spain, and by the 'Ministerio de Sanidad y Consumo, Instituto de Salud Carlos III' (Red RD06/0018/0017).

\section{Ethics committee}

Ethical approval was obtained from Sant Joan de Déu Foundation Ethics Board (Esplugues de Llobregat, Barcelona, Spain).

\section{Competing interests}

The authors have stated that there are none.

\section{Acknowledgements}

We are indebted to the GPs and patients who participated in this study. We are very grateful to Ms Cristina Molina, from the 'Departament de Salut - Generalitat de Catalunya', who conceived the DASMAP study.

\section{Discuss this article}

Contribute and read comments about this article on the Discussion Forum: http://www.rcgp.org.uk/bjgp-discuss

\section{REFERENCES}

1. Vedsted P, Christensen MB. Frequent attenders in general practice care: a literature review with special reference to methodological considerations. Public Health 2005; 119(2): 118-137.

2. Neal RD, Heywood PL, Morley S, et al. Frequency of patients' consulting in general practice and workload generated by frequent attenders: comparisons between practices. Br J Gen Pract 1998; 48(426): 895-898.

3. Báez K, Aiarzaguena JM, Grandes G, et al. Understanding patientinitiated frequent attendance in primary care: a case-control study. $\mathrm{Br}$ J Gen Pract 1998; 48(437): 1824-1827.

4. Lefevre F, Reifler D, Lee P, et al. Screening for undetected mental disorders in high utilizers of primary care services. J Gen Intern Med 1999; 14(7): 425-431.

5. Menchetti M, Cevenini N, De Ronchi D, et al. Depression and frequent attendance in elderly primary care patients. Gen Hosp Psychiatry 2006; 28(2): 119-124.

6. Ronalds C, Kapur N, Stone K, et al. Determinants of consultation rate in patients with anxiety and depressive disorders in primary care. Fam Pract 2002; 19(1): 23-28.

7. Vedsted P, Fink P, Olesen F, Munk-Jørgensen P. Psychological distress as a predictor of frequent attendance in family practice: a cohort study. Psychosomatics 2001; 42(5): 416-422.

8. Levinson CM, Druss BG. Health beliefs and depression in a group of elderly high utilizers of medical services. Gen Hosp Psychiatry 2005; 27(2): 97-99.

9. Roberts SJ. Psychosocial assessment of the high utilizer of occupational health services. AAOHN J 1990; 38(2): 62-66.

10. Foster A, Jordan K, Croft P. Is frequent attendance in primary care disease-specific? Fam Pract 2006; 23(4): 444-452.

11. Gill D, Sharpe M. Frequent consulters in general practice: a systematic review of studies of prevalence, associations and outcome. J Psychosom Res 1999; 47(2): 115-130.

12. Luciano JV, Serrano-Blanco A, Grupo DASMAP. Los hiperfrecuentadores en Atención Primaria: perfil sociodemográfico, características clínicas y propuesta de una nueva definición [Frequen user patients in primary care: Sociodemographic profile, clinical characteristics, and a proposed new definition]. Aten Primaria 2008; 40(12): 631-632.

13. Ciechanowski PS, Katon WJ, Russo JE. Depression and diabetes: impact of depressive symptoms on adherence, function, and costs. Arch Intern Med 2000; 160(12):3278-3285.

14. Serrano-Blanco A, Palao DJ, Luciano JV, et al. Prevalence of mental disorders in primary care: Results from the Diagnosis and Treatment of Mental Disorders in Primary Care Study (DASMAP). Soc Psychiatry Psychiatr Epidemiol 2009; 19 May epub ahead of print. 
15. First MB, Spitzer RL, Gibbon M, Williams JB. Structured Clinical Interview for Axis I DSM-IV Disorders, Research Version (SCID-RV). Washington, DC: American Psychiatric Press Inc, 1996.

16. Sheehan DV, Lecrubier Y, Sheehan KH, et al. The Mini-International Neuropsychiatric Interview (MINI): the development and validation of a structured diagnostic psychiatric interview for DSM-IV and ICD-10. J Clin Psychiatry 1998; 59(suppl 20): 22-33.

17. Ferrando L, Franco AL, Soto M, et al. MINI International Neuropsychiatric Interview. Spanish version 5.0.0. DSM-IV. Madrid: Instituto IAP, 1998.

18. Chisholm D, Knapp MRJ, Knudsen HC, et al. Client SocioDemographic and Service Receipt Inventory — European Version: development of an instrument for international research. EPSILON Study 5. European Psychiatric Services: Inputs Linked to Outcome Domains and Needs. Br J Psychiatry Suppl 2000; (39): s28-s33.

19. Guo G, Zhao H. Multilevel modeling for binary data. Annu Rev Sociol 2000; 26: 441-462.

20. Mickey RM, Greenland S. The impact of confounder selection criteria on effect estimation. Am J Epidemiol 1989; 129(1): 125-137.

21. Snijders TAB, Bosker RJ. Multilevel analysis. An introduction to basic and advanced multilevel modelling. London: Sage Publications, 1999.

22. Bhandari A, Wagner T. Self-reported utilization of health care services: improving measurement and accuracy. Med Care Res Rev 2006; 63(2): 217-235.

23. Kersnik J, Svab I, Vegnuti M. Frequent attenders in general practice: quality of life, patient satisfaction, use of medical services and GP characteristics. Scand J Prim Health Care 2001; 19(3): 174-177.

24. Neal RD, Heywood PL, Morley S. Frequent attenders' consulting patterns with general practitioners. Br J Gen Pract 2000; 50(461): 972-976.

25. Al-Windi A, Elmfeldt D, Svärdsudd K. The influence of sociodemographic characteristics on health care utilisation in a Swedish municipality. Ups J Med Sci 2004; 109(1): 33-42.

26. Scaife B, Gill P, Heywood P. Socio-economic characteristics of adult frequent attenders in general practice: secondary analysis of data. Fam Pract 2000; 17(4): 298-304.

27. Bellón JA, Delgado A, De Dios Luna J, Lardelli P. Psychosocial and health belief variables associated with frequent attendance in primary care. Psychol Med 1999; 29(6): 1347-57.

28. Al-Windi A. The influence of complaint symptoms on health care utilisation, medicine use, and sickness absence. A comparison between retrospective and prospective utilisation. J Psychosom Res 2005; 59(3): 139-146.

29. National Institute of Health and Clinical Excellence. Depression: management of depression in primary and secondary care. Clinical guideline 23. London: NICE; 2004.

30. Schulze B. Stigma and mental health professionals: a review of the evidence on an intricate relationship. Int Rev Psychiatry 2007; 19(2): 137-55.

31. Bellón JA, Rodríguez-Bayón A, de Dios Luna, J, Torres-González F. Successful GP intervention with frequent attenders in primary care: randomised controlled trial. Br J Gen Pract 2008; 58(550): 324-330. 